\title{
On the use of simultaneous measurements of $\mathrm{OH}$ and $\mathrm{O}_{2}$ emissions to investigate wave growth and dissipation
}

\author{
A. Taori ${ }^{1}$, A. Guharay ${ }^{1}$, and M. J. Taylor ${ }^{2}$ \\ ${ }^{1}$ Aryabhatta Research Institute of Observational Sciences, Nainital, India \\ ${ }^{2}$ Department of Physics, Utah State University, Logan, UT, USA
}

Received: 22 August 2006 - Revised: 16 February 2007 - Accepted: 12 March 2007 - Published: 29 March 2007

\begin{abstract}
Simultaneous measurements of mesospheric $\mathrm{OH}(6-2)$ Meinel and $\mathrm{O}_{2}(0-1)$ Atmospheric band emissions from a low-latitude station, Maui, Hawaii $\left(20.8^{\circ} \mathrm{N}\right.$, $156.2^{\circ} \mathrm{W}$ ) are utilized to study the wave characteristics and associated processes. Deduced temperatures show large variability in both $\mathrm{OH}$ and $\mathrm{O}_{2}$ data. The seasonal variability in the temperature shows a well-defined, semiannual type of oscillation, which are comparable to the ground-based rocket sounding data. The "Wave Growth Factor", a ratio of normalized perturbation amplitude in $\mathrm{O}_{2}$ to the $\mathrm{OH}$ temperature variability, is estimated for principal as well as residual smaller period components of the nocturnal variability. It is noticed that smaller period waves (less than $12 \mathrm{~h}$ ) occasionally have large growth factors of about 3-4 during equinox transitions, an indication of wave amplitude amplification within the $87-94 \mathrm{~km}$ altitudes while a strong wavedissipation occurs throughout the year.
\end{abstract}

Keywords. Ionosphere (Equatorial ionosphere) - Atmospheric composition and structure (Airglow and aurora) Meteorology and atmospheric dynamics (Middle atmosphere dynamics)

\section{Introduction}

Airglow emissions are an outcome of the chemiluminescence property of various atomic and molecular species in the middle and upper atmosphere. In recent times, airglow emission variability at different wavelengths has been widely used to infer the mesosphere-lower thermosphere-ionosphere behavior (Fagundes et al., 1995; Takahashi et al., 1998; Mukherjee, 2003; Reisin and Scheer, 2004; Taori et al., 2005). It is found that the emission intensity and deduced temperature variability are dominated

Correspondence to: A. Taori

(ataori@aries.ernet.in) by a long period as well as short period structures that are commonly attributed to the passage of atmospheric waves, i.e. gravity waves and tides.

It is generally understood that these gravity waves and tides are of lower atmospheric origin. They propagate upwards and play an important role in the lower and upper atmosphere coupling processes (Murthy, 1998). During their propagation, they interact with the mean winds and other wave modes, which lead them to deposit heat and momentum in the ambient and to modify the dynamical conditions at those altitudes (Fritts et al., 2006). Further, at mesospheric altitudes the amplitudes of these waves become several times larger than that at the lower atmosphere in order to conserve energy $\left(\rho v^{2} / 2=\right.$ constant $)$. Consequently, waves and associated processes dominate the dynamical variability at mesopause levels (Fritts et al., 2003).

Often, it is the propagation characteristics of gravity waves (e.g. phase velocity, vertical wavelength and time period) that have been investigated using multi-wavelength airglow monitoring (e.g. Fagundes et al., 1995; Takahashi et al., 1998; Taori et al., 2005). The gravity wave characterization has also been carried out using simultaneous measurements of the airglow intensity and temperatures as the ratio of percentage perturbation amplitude of wave in intensity to their temperature counterparts (Reisin and Scheer, 1996; Taori and Taylor, 2006). Although significant progress has been made on the use of airglow emissions to study the gravity wave and tides, very little has been understood when it comes to the inferring dissipation processes using the airglow emissions. In this area, Noxon (1978) was first to use simultaneous measurements of the $\mathrm{OH}$ and $\mathrm{O}_{2}$ layers to infer the wave growth and dissipation, which was later followed up by Reisin and Scheer (1996). Both of the above studies report a high degree of variability in the wave amplitude growth within the short altitude range of $7 \mathrm{~km}$ (i.e. the separation altitude between the $\mathrm{OH}$ and $\mathrm{O}_{2}$ emission layers). The present paper uses an extensive database of more than 400 nights of

Published by Copernicus GmbH on behalf of the European Geosciences Union. 


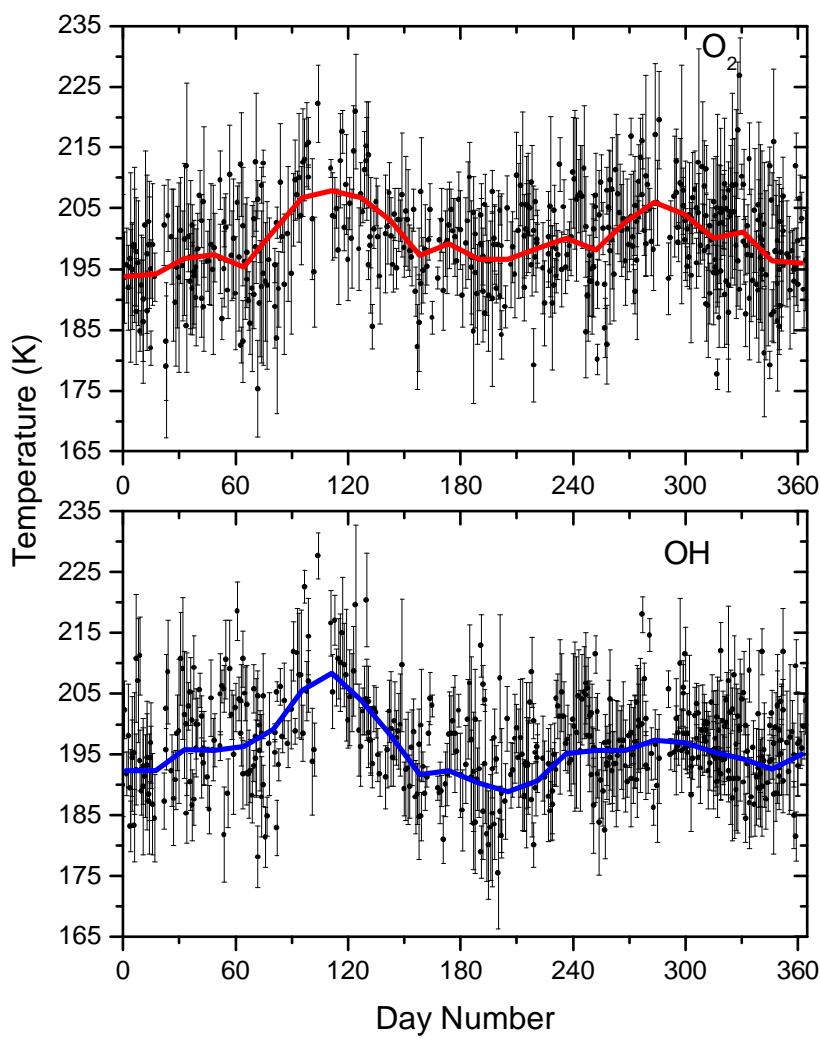

Fig. 1. Composite yearly plot of the Hawaii data by Taylor et al. (2005). The top panel represents $\mathrm{O}_{2}$ while the bottom panel represents the $\mathrm{OH}$ temperature data. Solid lines in the plot represent a 15-day averaged data. Both data show a well-defined, semiannual oscillation with maxima during the spring and autumn periods. The asymmetry in the spring to the autum peaks is evident in the data.

quality mesospheric $\mathrm{OH}$ and $\mathrm{O}_{2}$ temperature measurements from Hawaii $(20.8 \mathrm{~N}, 156.2 \mathrm{~W})$. Reported herein are the preliminary results on wave-packet growth/decay related to the dissipation processes occurring at mesospheric altitudes.

\section{Instrument and observations}

The Mesospheric Temperature Mapper (MTM) is a high performance, solid-state imaging instrument that utilizes a large format $\left(6.45 \mathrm{~cm}^{2}\right)$, a $1024 \times 1024$ pixel CCD array coupled to a $90^{\circ}$ circular field of view telecentric lens system. The high quantum efficiency ( $\sim 50 \%$ at near-infrared wavelengths) and low noise characteristics (dark current $\sim 0.1 \mathrm{e}^{-} / \mathrm{pixel} / \mathrm{s}$ at $-50^{\circ} \mathrm{C}$ ) of the $\mathrm{CCD}$ array provide an exceptional capability of high quality nocturnal measurements of $\mathrm{OH}$ and $\mathrm{O}_{2}$ emission intensity ( $<0.5 \%$ in $1 \mathrm{~min})$ and derived rotational temperatures (precision $<1-2 \mathrm{~K}$ in $3 \mathrm{~min}$ ). The details of this instrument are discussed elsewhere (Pendleton et al., 2000; Taylor et al., 2001).

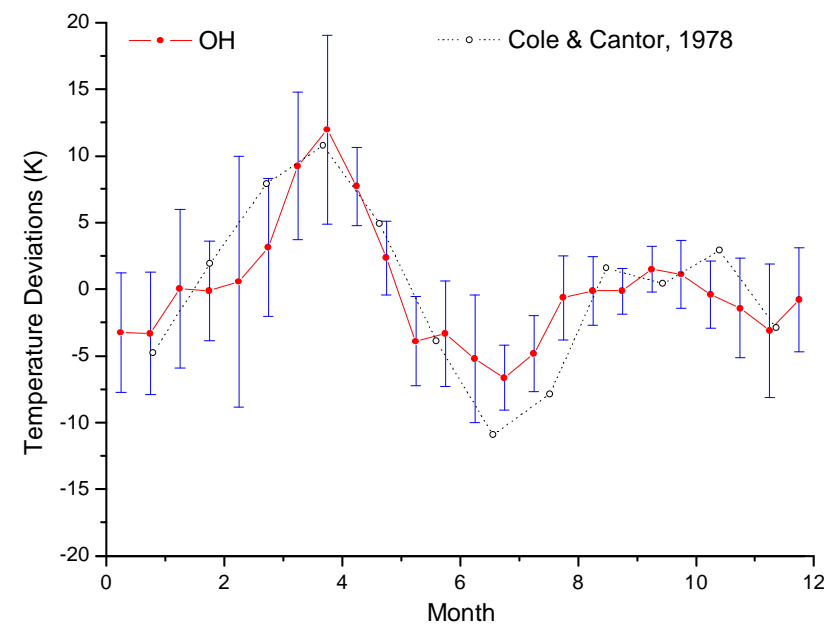

Fig. 2. The comparison plot of the mean temperature deviations for the 15-day binned $\mathrm{OH}$ data and the temperature deviations obtained by Cole and Cantor (1978). One could see remarkable similarities in the temperature variability.

Since the deployment of MTM in November 2001 at the air force AEOS facility at the summit of Haleakala Crater, Maui $(20.8 \mathrm{~N}, 156.2 \mathrm{~W})$, routine measurements of the $\mathrm{OH}(6-$ 2) Meinel band and $\mathrm{O}_{2}(0-1)$ the Atmospheric band emission have been carried out. The present article is based on the 467 clear nights of observation with data length of at least $4 \mathrm{~h}$ over a 26-month period (November 2001-January 2004).

\section{Results and discussion}

Figure 1 is a composite plot of the seasonal variability in the mesospheric $\mathrm{OH}$ and $\mathrm{O}_{2}$ temperatures reported by Taylor et al. (2005). Vertical bars in the plot represent the standard deviation on their nightly mean temperature (solid circles), which is representative of the average perturbation amplitude caused by the wave packet on that night. The wave packet would include a spectrum of waves consisting of a long period as well as shorter period perturbations present in the data on that night. One can notice that temperature data broadly ranged from 185 to $215 \mathrm{~K}$ (mean value $199.6 \mathrm{~K}$ ) for $\mathrm{O}_{2}$ while the $\mathrm{OH}$ temperature was around $175 \mathrm{~K}$ to $220 \mathrm{~K}$, with a mean value of $196.9 \mathrm{~K}$. In their report, Taylor et al. (2005) concluded the periodicity of the dominant variation to be near 180 days, exhibiting a semiannual-type oscillation in the mesospheric temperatures. Further, a 15-day averaging of the mean temperatures was carried out to clearly bring out the seasonal pattern and the results are shown in plots as connecting solid lines. In particular, $\mathrm{OH}$ temperature data (mean $196.9 \mathrm{~K}$ ) was compared with the existing data set of Cole and Cantor (1978) for $90 \mathrm{~km}$ altitudes at $15^{\circ} \mathrm{N}$ latitudes, which used meterological rocket sounding (Fig. 2). The error bars in the MTM data represents the standard deviations 



Fig. 3. (a, b) The mean temperature deviations for the $\mathrm{O}_{2}$ emissions and $\mathrm{OH}$ emissions on UT day 48, 2002. The solid line curve is the result of a best-fit sinusoidal analysis. A long period tide-like oscillation is evident in the data with periodicity of about $12 \mathrm{~h}$. The temperature residuals are plotted in the right panels $(\mathbf{c}, \mathbf{d})$. Note the large variations in the smaller period wave perturbations with periods ranging from $10 \mathrm{~min}$ to $6 \mathrm{~h}$.

on the 15-day average data (a measure of variability). Agreement in the seasonal variability in two different data sets, one collected by ground-based MTM and another rocket-borne in-situ measurements is noteworthy. Not only the semiannual type of oscillation feature but also the asymmetry in the spring to autumn peaks is evident in the MTM data. Further, a best-fit analysis revealed the perturbation amplitude of this semiannual type of oscillation to be about $5-6 \mathrm{~K}$ in both the $\mathrm{OH}$ and $\mathrm{O}_{2}$ temperatures.

Apart from the seasonal variability in the data, large values of standard deviations are often noted in the plot (of about $10-15 \mathrm{~K}$ on their nightly mean temperatures), vindicating the perturbation amplitude on those nights to be very large (essentially caused by the spectrum of waves ranging from periods of a few minutes to several hours). To verify the same, Fig. 3 presents a sample analysis of the $\mathrm{OH}$ and $\mathrm{O}_{2}$ temperature data for UT day 048, 2002 (16-17 February) (one of those nights with large standard deviation). The left-hand panel plots the temperature variability around their means (nightly mean values: $196.9 \mathrm{~K}$ for $\mathrm{O}_{2}$ and $194.9 \mathrm{~K}$ for $\mathrm{OH}$ ) for the $\mathrm{O}_{2}$ (top) and $\mathrm{OH}$ (bottom) emissions. One could see a dominant long period oscillatory feature in the data, together with embedded shorter period features. Also evident in the data is a phase delay of about $1 \mathrm{~h}$ between the $\mathrm{O}_{2}$ and $\mathrm{OH}$ temperature peaks, exhibiting a downward phase progression, consistent with the upward propagation of a gravity wave. To estimate the amplitudes of the oscillation, a simple best-fit cosine model was used on the mean temperature deviations, as described in the following equation:

$Y=A \operatorname{Cos}\left[\pi \frac{(X-X c)}{W}\right]$,

where $A$ is the amplitude of the fitted wave of half-period $W$ with phase $X c$, and $X$ is the time.

The above analysis revealed the presence of a dominant $\sim 12 \pm 0.4 \mathrm{~h}$ wave in the data with a perturbation amplitude of $\sim 17 \mathrm{~K}$ in the $\mathrm{O}_{2}$ and $\sim 6 \mathrm{~K}$ in the $\mathrm{OH}$ temperatures. Analogous to the RS filter analysis described by Gavrilov (1995) for the radar wind data, we plot the residuals deduced from the best-fit analysis in the right-hand panel for both the $\mathrm{OH}$ (bottom) and $\mathrm{O}_{2}$ (top) temperatures with their standard deviations being a measure of shorter period (a few minutes to less than $12 \mathrm{~h}$ ) wave amplitudes (i.e. wave-packet amplitude). On this day, standard deviations on the residual temperature were $2.14 \mathrm{~K}$ and $2.68 \mathrm{~K}$ in $\mathrm{OH}$ and $\mathrm{O}_{2}$, respectively. Note here that the separation between these layers (i.e. $\mathrm{OH}$ and $\mathrm{O}_{2}$ ) is $\sim 7 \mathrm{~km}$; hence, for an upward propagating wave, one would expect an amplification in the wave amplitude due to decreasing density and to conserve energy (Reisin and Scheer, 1996; Taori et al., 2005). Therefore, a theoretical estimate can be made on the amplitude growth for an upward propagating wave. Assuming an upward propagating wave 

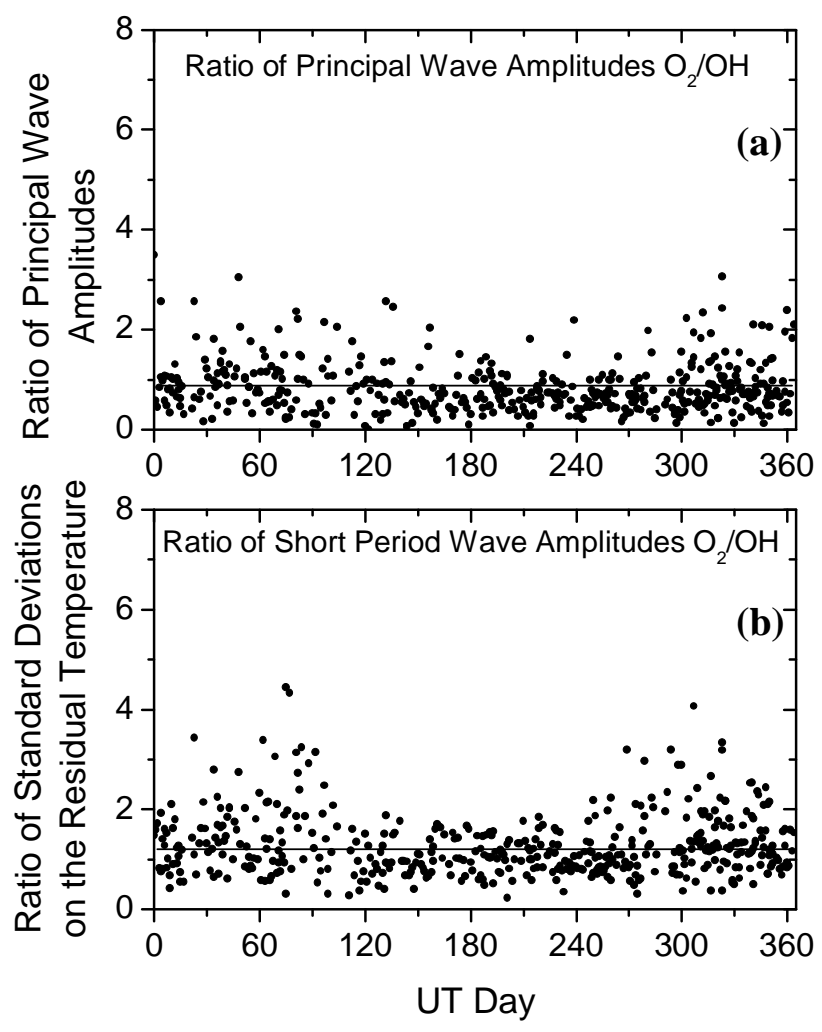

Fig. 4. The top panel shows the ratio of the principal wave amplitudes in $\mathrm{O}_{2}$ to the $\mathrm{OH}$ data (normalized to their mean values). The ratios of the standard deviations $\left(\mathrm{O}_{2} / \mathrm{OH}\right)$ normalized to their mean are plotted in the bottom panel. Solid lines in the plots represent $95 \%$ confidence levels. One could see the difference in the seasonal pattern in the growth factors between both the plots with smaller period waves, having notable variability from the equinox to the summer time.

with a unit amplitude at ground level, under a dissipationless atmospheric condition with a scale height of $7 \mathrm{~km}$, the wave growth factor should be around 1.4 and any deviations from this number would indicate towards either wave dissipation/growth. Although the growth factor would also depend on the scale sizes of a wave, the above factor is only for a relative comparison. For the data presented in Fig. 3 the amplitude growth (i.e. growth factor) (defined as the ratio of percentage variations in $\mathrm{O}_{2}$ to the $\mathrm{OH}$ data) works out to be $\sim 2.8$ for long period wave and 1.25 for the shorter period waves. Therefore, the deduced wave growth of 2.8 and 1.25 for principal and shorter period wave-packets implies a significant growth for the principal wave and dissipation for shorter period waves on this day.

Further, to examine the seasonal pattern in the wave growth within the altitude range of the $\mathrm{OH}$ and $\mathrm{O}_{2}$ emission layers (i.e. $85-95 \mathrm{~km}$ ), we carried out this analysis on all the nights presented in Fig. 1 and the results are plotted in Fig. 4. Results on the wave-growth for the principal temperature wave for each day are shown in Fig. 4a, while Fig. 4b represents the ratios of the standard deviations on the residual temperatures normalized to their residual means (measure of the wave growth for waves with periods less than $12 \mathrm{~h}$ ). To better avoid any statistical and instrumental errors, we plot the $95 \%$ confidence levels in both figures ( 0.89 and 1.34 in panels a and $b$, respectively). We see that growth factors for the principal waves are mostly below 2, with very little or no significant seasonal variability pattern in the data, vindicating a less evident seasonal pattern in the principal wave growth. This could be because of large vertical wavelengths of principal waves, which are mostly dominated by the large period tide - like waves and hence, the inefficiency of the $\mathrm{OH}$ and $\mathrm{O}_{2}$ layers is separated by only $7 \mathrm{~km}$ to detect the wave growth. However, when looked at carefully, a different picture emerges for the waves with smaller periodicities. The growth factors ranged from 0.5 to 4 with a significant wavepacket growth around day number 75 and 300 . During these days, several smaller waves (about $18 \%$ during day number 60 to 100 and around $14 \%$ during $270-310$ ) were found to attain significant growth in their amplitudes. However, during summer almost all the smaller waves have no significant amplitude growth. Along similar lines, Reisin and Scheer (1996) have reported the wave-growth values from 0.9 to 1.7 obtained from observations at mid-latitudes on individual nights, at different times of the year, which is a much smaller range than reported here, indicating higher variability in our data from low latitudes.

In short, the data presented in the present paper show a large variability in the wave growth with summer being dominated by the strong dissipative processes and significant wave growth occurring near equinox. In turn, this means that equinox is the season when wave penetration can take place through the mesospheric altitudes to reach higher above. It should be noted that the equinox offers a transition for the prevailing wind conditions, which would cause a subdued wind-wave filtering process and reduced dissipative mechanism, resulting in more wave-influx higher above (Lindzen, 1981). Some of these waves, specifically shorter period waves (Vadas and Fritts, 2005), may have the potential to reach the upper mesosphere, which is the base of the thermosphere-ionosphere system and possibly become a seeding perturbation for equatorial spread F (ESF) (Sridharan, 1998). However, to strengthen these preliminary results on wave-growth, long-term, multi-instrumentation campaigns are required to understand the gravity wave and tidal dynamics and their effects on the mesosphere - lower thermosphere - ionosphere system.

Acknowledgements. The present analysis work is supported by ARIES (an autonomous institute under DST, Govt. of India). Authors thank Director, ARIES for his continuous support. Data collection was carried out as a part of ongoing joint program between the Air Force Office of Scientific Research (AFOSR) and the National Science Foundation (NSF). Financial support for the measurements and data analysis was provided by NSF grant ATM 0003218. A. Taori was supported by CEDAR post-doctoral fellowhip (NSF grant ATM 0134150). 
Topical Editor U.-P. Hoppe thanks P. R. Fagundes and another referee for their help in evaluating this paper.

\section{References}

Cole, A. J. and Cantor, A. J.: Tropical Atmospheres, 0 to $90 \mathrm{~km}$, Project 8624, Tech. Rep. AFCRL-TR-75-0527, Aeron. Lab., Air Force Cambridge Res Lab., Hanscom, Mass., 1978.

Fagundes, P. R., Takahashi, H., Sahai, Y., and Gobbi, D.: Observations of gravity waves from multispectral mesospheric nightglow emissions observed at $23^{\circ} \mathrm{S}$, J. Atmos. Sol. Terr. Phys., 57(4), 395-405, 1995.

Fritts, D. C. and Alexander, M. J.: Gravity wave dynamics and effects in the middle atmosphere, Rev. Geophys., 41, 1, doi:10.1029/2001RG000106, 2003.

Fritts, D. C., Vadas, S. L., Wan, K., and Werne, J. A.: Mean and variable forcing of the middle atmosphere by gravity waves, J. Atmos. Sol. Terr. Phys., 68, 247-265, 2006.

Gavrilov, N. M., Manson, A. H., and Meek, C. E.: Climatological monthly characteristics of middle atmosphere gravity waves (10 min-10 h) during 1979-1993 at Saskatoon, Ann. Geophys., 13, 285-295, 1995, http://www.ann-geophys.net/13/285/1995/.

Lindzen, R. S.: Turbulence and stress owing to gravity wave and tidal breakdown, J. Geophys. Res., 86, 9707-9714, 1981.

Mukherjee, G. K.: The signature of short-period gravity waves imaged in the OI $557.7 \mathrm{~nm}$ and near infrared $\mathrm{OH}$ nightglow emissions over Panhala, J. Atmos. Sol. Terr. Phys., 65, 1329-1335, 2003.

Murthy, B. V. K.: Middle atmosphere - upper atmosphere coupling, Proceedings of Indian National Science Academy, 64, A, 3, $303-$ 313, 1998.

Noxon, J. F.: Effects of internal gravity waves upon night airglow temperatures, Geophys. Res. Lett., 5(1), 25-27, 1978.

Pendleton, W. R., Taylor, M. J., and Gardner, L. C.: Terdiurnal oscillations in $\mathrm{OH}$ Meinel rotational temperatures for fall conditions at northern mid-latitude sites, Geophys. Res. Lett., 27(12), 1799-1802, 2000.
Reisin, E. R. and Scheer, J.: Characteristics of atmospheric waves in the tidal period range derived from zenith observations of $\mathrm{O}_{2}$ (0-1) Atmospheric and $\mathrm{OH}$ (6-2) airglow at lower midlatitudes, J. Geophys. Res., 101, 21 223-21 232, 1996.

Reisin, E. R. and Scheer, J.: Gravity wave activity in the mesopause region from airglow measurements at El Leoncito, 66, 655-661, 2004.

Sridharan, R.: Equatorial and low latitude thermosphere - ionosphere interaction, Proceedings of Indian National Science Academy, 64, A, 3, 315-340, 1998.

Takahashi, H., Gobbi, D., Batista, P. P., Melo, S. M. L., Teixeira, N. R., and Buriti, R. A.: Dynamical influence on the equatorial airglow observed from the south American sector, Adv. Space Res., 21(6), 817-825, 1998.

Taori, A., Taylor, M., and Franke, S.: Detection and measurement of a terdiurnal wave signature in the upper mesospheric temperature and wind fields at low latitudes $\left(20^{\circ} \mathrm{N}\right)$, J. Geophys. Res., 110, D09S06, doi:10.1029/2004JD004564, 2005.

Taori, A. and Taylor, M.: Characteristics of wave induced oscillations in mesospheric $\mathrm{O} 2$ emission intensity and temperatures, Geophys. Res. Lett., 33, L01813, doi:10.1029/2005GL024442, 2006.

Taylor, M. J., Gardner, L. C., and Pendleton Jr., W. R.: Long period wave signatures in mesospheric $\mathrm{OH}$ Meinel $(6,2)$ band intensity and rotational temperature at mid latitudes, Adv. Space Res., 27(6-7), 1171-1179, 2001.

Taylor, M. J., Taori, A., Hatch, D. R., Liu, H. L., and Roble, R. G.: Characterization of the Semi-Annual-Oscillation in Mesospheric Temperatures at Low-Latitudes, Adv. Space Res., 35, 2037-2043, 2005.

Vadas, S. L. and Fritts, D. C.: Thermospheric responses to gravity waves : Influence of increasing viscosity and thermal diffusivity', J. Geophys. Res., 110, D15103, doi:10.1029/2004JD005574, 2005. 